\title{
Cadmium Uptake and Distribution in Fragrant Rice Genotypes and Related Consequences on Yield and Grain Quality Traits
}

\author{
Adam Sheka Kanu, ${ }^{1,2}$ Umair Ashraf, ${ }^{1}$ Zhaowen Mo, ${ }^{1}$ Issaka Fuseini, ${ }^{3}$ Lamin R. Mansaray, \\ Meiyang Duan, ${ }^{1}$ Shenggan Pan, ${ }^{1}$ and Xiangru Tang ${ }^{1}$ \\ ${ }^{1}$ Department of Crop Science and Technology, College of Agriculture, South China Agricultural University, Guangzhou 510642, China \\ ${ }^{2}$ Rokupr Agricultural Research Centre (RARC), Sierra Leone Agricultural Research Institute (SLARI), PMB 1313, \\ Freetown, Sierra Leone \\ ${ }^{3}$ Department of Environmental Science and Engineering, College of Natural Resource and Environment, \\ South China Agricultural University, Guangzhou, China \\ ${ }^{4}$ Magbosi Land, Water and Environment Research Centre (MLWERC), Sierra Leone Agricultural Research Institute (SLARI), \\ PMB 1313, Freetown, Sierra Leone
}

Correspondence should be addressed to Xiangru Tang; tangxr@scau.edu.cn

Received 11 December 2016; Revised 18 March 2017; Accepted 4 April 2017; Published 29 May 2017

Academic Editor: Abdul Khaliq

Copyright (C) 2017 Adam Sheka Kanu et al. This is an open access article distributed under the Creative Commons Attribution License, which permits unrestricted use, distribution, and reproduction in any medium, provided the original work is properly cited.

Cadmium (Cd) toxicity has varying consequences on plants growth and development. This research focused on examining the influence of Cd toxicity on fragrant rice genotypes and its consequences on yield, yield related parameters, and grain quality traits. Randomized complete block design comprising five different fragrant rice cultivars (Meixiangzhan 2, Xiangyaxiangzhan, Guixiangzhan, Basmati, and Nongxiang 18) and four Cd levels $(0,50,100$, and $150 \mathrm{mg} / \mathrm{kg}$ soil) was used. The results showed that, with increased levels of soil Cd toxicity, Cd uptake in roots and distribution to other organs increased in dose dependent manner. Uptake and accumulation were higher in roots than in shoots with the highest uptake in both roots and shoots observed in Meixiangzhan 2, followed by Nongxiang 18, Basmati, Xiangyaxiangzhan, and Guixiangzhan cultivars. With increased Cd toxicity, yield and yield parameters were affected in all cultivars. Grain quality was also found affected under Cd stress condition. The results suggested that soil Cd toxicity has negative consequences on rice performance and uptake varies among cultivars. Conclusively, Cd toxicity impaired rice yield formation and grain quality by altering yield components (panicles number, spikelet per panicles, and spikelet setting (\%)); however, Guixiangzhan variety performed better, while Meixiangzhan 2 performed less in terms of minimum Cd uptake and distribution to grains, yield, and grain quality reduction under Cd stress condition.

\section{Introduction}

Cadmium (Cd) is among the most toxic heavy metals deposited in agricultural soils through natural means and man-made activities like the application of sewage sludge containing Cd contents, application of phosphate fertilizers, and waste disposal as well as metal smelting $[1,2]$. Cadmium toxicity in agricultural soils is a serious threat to crop production worldwide [3]. Even at low concentration and due to its nonessential form in living organisms, $\mathrm{Cd}$ becomes highly toxic to both growing plant and animals, thus, affecting plant morphologically, physiologically, and biochemically during growth. Cadmium can be taken up by rice roots and then translocated to shoots and grains of growing rice [4]. The most common visible symptoms of $\mathrm{Cd}$ toxicity in growing rice plants include reduction in plant growth and development, chlorosis, and eventually plant death. High $\mathrm{Cd}$ accumulation in rice consumed by animals, especially humans, poses several health implications such as cardiac failure, anemia, cancer, hypertension, emphysema, proteinuria, cerebrovascular infarction, damage to the lungs, renal dysfunction in eyes, and osteoporosis $[5,6]$. Cadmium 
translocation from soil to roots and shoot and finally to the edible plant parts is often the easiest pathway through which Cd enters the human body [7]. Research has shown that nearly sixteen percent $(16 \%)$ of the agricultural soils in China have been polluted by varying heavy metals, and Cd has polluted approximately $1.3 \times 105 \mathrm{hm}^{2}$ and $1.46 \times 108 \mathrm{~kg}$ of the soils and agricultural products, respectively; this also included 50000 tons of rice [8].

Rice (Oryza sativa L.) is a major cereal crop cultivated and consumed worldwide; it is the second most important cereal crop after wheat in terms of area cultivated and consumption rate [9]. Rice growth and development are eminent at all stages for ensuring seedlings development and yield formation. At the vegetative stage, rice growth comprises roots development for nutrients uptake, hypocotyl elongation, and enzymes activation for mobilizing stored energy and nutrients as well as photosynthetic processes, whereas the reproductive stage in rice growth enables maximum yield formation. Heavy metals in paddy soils affect rice growth and performance; for instance, Cd stress has been proven to affect plants morphologically and physiologically as well as disrupting antioxidants enzymes in rice seedlings under polluted soils. Reports have shown reduction in rice growth and biomass, which might possibly be as a result of different Cd-mediated toxicity mechanisms in rice [10]. Various other studies have also reported that the toxic effects of $\mathrm{Cd}$ increased rice seedlings oxidative stress by releasing reactive oxygen species (ROS) like malondialdehyde (MDA) contents, hydrogen peroxide $\left(\mathrm{H}_{2} \mathrm{O}_{2}\right)$, and electrolyte leakage which affects rice growth and performance $[10,11]$. Cadmium toxicity also altered leaf and root ultrastructure and caused structural damage to photosynthetic apparatus of rice [12].

From several other studies conducted, marked differences in Cd uptake and translocation among plant species as well as among cultivars within the same species were observed $[6,12$, 13].

During rice growth, $\mathrm{Cd}$ toxicity levels in soils and potential damage to plants are difficult to establish due to the susceptibility and tolerant abilities of some cultivars. Cd translocation from soil to plant organs is an important factor in identifying specific cultivars and concentration level considered toxic for varying rice cultivars. Different cultivars showed differential response regarding Cd uptake and transport under heavy metal stress conditions; however their response does vary based on concentration and cultivar genotypic storage and translocation potential [14]. Furthermore, the tolerance and sensitivity indices of a specific rice cultivar are related to root $\mathrm{Cd}$ storage ability and its speciation in above-ground plant parts. Considering the importance attached to fragrance rice by its desirable consumers as well as its high market value, it has become necessary to evaluate the response of different scented rice cultivars to varying levels of cadmium toxicity. Hence, the need for this research study is to evaluate the effect of varying $\mathrm{Cd}$ toxicity on five selected rice cultivars in China. Identifying rice cultivars with minimal Cd accumulating character in roots and with less translocation ability in other parts might be a better option to grow rice in Cd toxic soils.

\section{Materials and Methods}

2.1. Experimental Design and Treatments Application. Pot experiment was conducted in rain protected greenhouse under open-air conditions at the experimental research farm (College of Agriculture, South China Agricultural University), Guangzhou city $\left(23^{\circ} 14^{\prime} \mathrm{N}, 113^{\circ} 37^{\prime} \mathrm{E}, 20 \mathrm{M}\right.$ altitude), during 2015/2016 cropping years. Paddy soil from the research farm was collected to a depth of $20 \mathrm{~cm}$. The air dried soil sample was sieved through a $4 \mathrm{~mm}$ sieve, mixed thoroughly, and filled in the pots ( $25 \mathrm{~cm}$ diameter $\times 30 \mathrm{~cm}$ height). About $10 \mathrm{~kg}$ soil was filled in each pot and $\mathrm{Cd}(1.5,2.2$, and $3.0 \mathrm{~g})$ in the form of $\mathrm{CdCl}_{2} \cdot 2.5 \mathrm{H}_{2} \mathrm{O}$ was added to the soil to obtain the required soil $\mathrm{Cd}$ concentrations of 50,100 , and $150 \mathrm{mg} / \mathrm{kg}$, respectively. $\mathrm{Cd}=0 \mathrm{mg} / \mathrm{Kg}$ was added as control. The pots once filled with soil were thoroughly mixed with the exact amount of $\mathrm{Cd}\left(\mathrm{CdCl}_{2} \cdot 2.5 \mathrm{H}_{2} \mathrm{O}\right)$ based on the treatment and kept for 15 days before seedlings were transplanted in them. The pots were arranged in a randomized complete block design (RCBD) with each treatment replicated three times. The soil used for the experiment was analyzed and was found to contain $4.96 \mathrm{mg} / \mathrm{kg} \mathrm{Cd}$ content, $5.92 \mathrm{pH}$ level, and $18.73 \mathrm{~g} / \mathrm{kg}$ organic matter contents, while total NPK was 0.81 , 0.9 , and $16.79 \mathrm{~g} / \mathrm{kg}$, and available NPK was $69.15,10.15$, and $109.62 \mathrm{mg} / \mathrm{kg}$, respectively.

2.2. Rice Cultivars Preparation. The five aromatic rice varieties, namely, Meixiangzhan 2 (V1), Xiangyaxiangzhan (V2), Guixiangzhan (V3), Basmati (V4), and Nongxiang 18 (V5), were secured from the Department of Crop Science and Technology, College of Agriculture, South China Agricultural University (SCAU), Guangzhou. Rice seeds were first soaked in deionized water for about $48 \mathrm{hrs}$ at room temperature $\left(25-28^{\circ} \mathrm{C}\right)$ and nursed on March 3, 2015, in an uncontaminated soil using parachute trays under moist conditions. After 30 days (April 3, 2015), the seedlings were transplanted into the pots ( 4 seedlings per pot). The pots were maintained under flooded conditions of $2-3 \mathrm{~cm}$ water level above the soil surface during the entire growth period. Recommended rates of fertilizers were split-applied as basal application prior to transplanting and were top-dressed 5 weeks after transplanting. Samples for Cd uptake in rice organs were collected at panicle heading and maturity stages. Entire rice was harvested and yield parameters were measured at maturity. The samples were separated into roots, stems leaves, and grains and were oven-dried at $80^{\circ} \mathrm{C}$ to constant weight for analysis of plants Cd uptake in roots, stems, leaves, and grains.

2.3. Yield and Its Components. During maturity stage, three pots from each treatment were randomly selected. Rice plants from each treatment pot were manually harvested using sickle and then threshed. The paddy was sun-dried to moisture content and grain yield per pot determined and expressed in grams per pot $\left(\mathrm{g} p o t^{-1}\right)$. Total panicles per pot were counted for each treatment and means recorded. Filled and unfilled grains were separated and counted manually from each panicle to obtain total number of filled and unfilled grains per panicle. 1000-grain weight was recorded by weighing randomly sampled 1000 filled grains. 


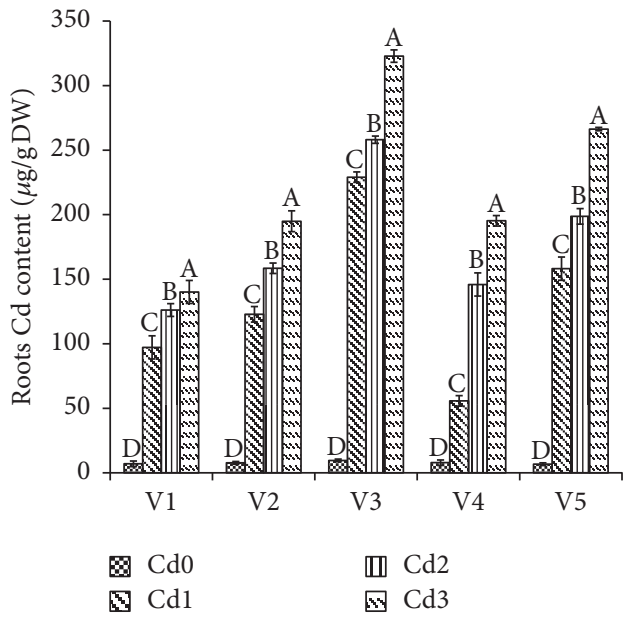

(a)

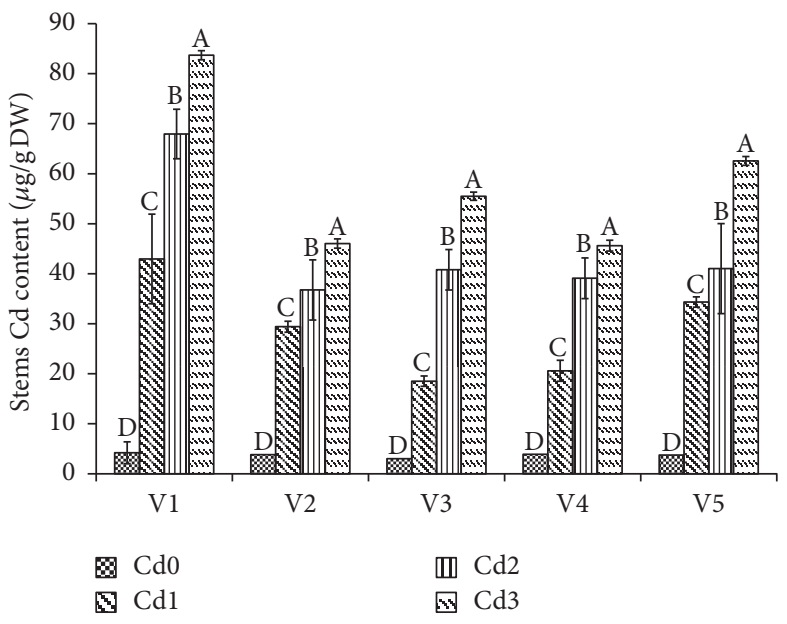

(b)

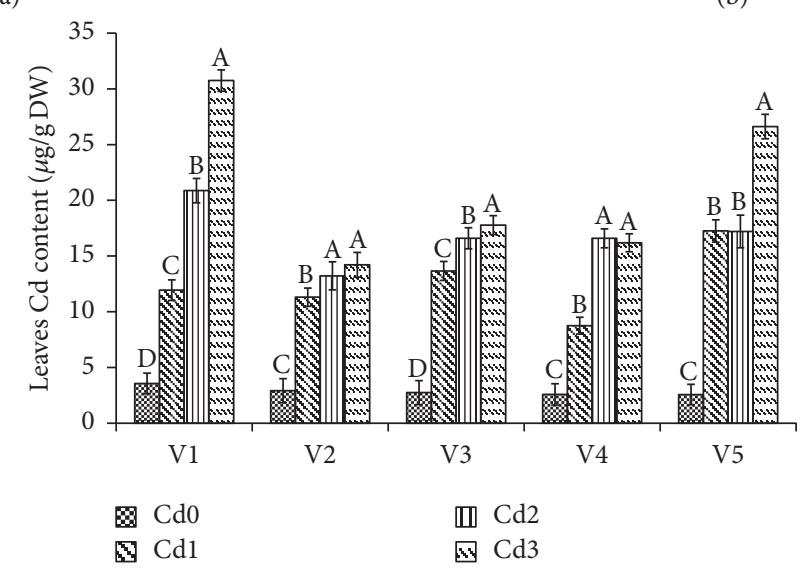

(c)

FIGURE 1: Cd uptake in (a) roots, (b) stems, and (c) leaves of the five different rice cultivars under induced Cd stress at panicle heading stage. The values are representative of three replicated means per treatment \pm SE. Different letters indicate significant differences between treatments at $P \leq 0.05$, LSD.

2.4. Grain Quality Estimation. Grain quality determination was carried out after harvesting, threshing, and sun-drying of rice. Rice grains were then stored at room temperature for a period of three months to determine their quality traits. About $500 \mathrm{~g}$ of rice grain from each treatment was weighed from the stored grains. Brown rice rate was estimated using a rice huller (Jiangsu, China) while milled rice and head rice rates were measured with a Jingmi testing rice grader (Zhejiang, China). Grains chalkiness degree was determined using an SDE-A light box (Guangzhou, China). Grain protein and amylose contents were measured using an Infratec 1241 grain analyzer (FOSS-TECATOR).

\subsection{Determination of Cd Content and Translocation Factor} between Rice Organs. Cadmium content in rice roots, stems, leaves, and grains was determined by separating entire plant into roots, stems, leaves, and grains and then dried in an oven at $80^{\circ} \mathrm{C}$ till constant weight. The oven dried plant parts of each were then ground into powdered form using stainless steel grinders. About $0.2 \mathrm{~g}$ of the ground samples was weighed for each treatment and digested with di-acid mixture of $\mathrm{HNO}_{3}: \mathrm{H}_{2} \mathrm{O}_{2}(4: 1 v / v)$, and the resultant solutions were diluted to $25 \mathrm{ml}$ and then filtered using Whatman filter papers. The $\mathrm{Cd}$ concentrations in the filtrate were then determined using an Atomic Absorption Spectrophotometer (AA6300C, Shimadzu, Japan). The translocation factor (TF) for Cd among roots, shoot, leaves, and grains was calculated by estimating the compartment concentration of $\mathrm{Cd}$ in one part with respect to the other parts as described by [15].

2.6. Statistical Analysis. The data obtained in this study were analyzed using Microsoft excel 2007 and subjected to oneway analysis of variance (ANOVA) and the mean differences were compared by Fisher's LSD using Statistix 8 (Analytical, Tallahassee, Florida, USA). Differences at $P<0.05$ were considered significant.

\section{Results}

3.1. Cadmium Uptake and Distribution in Different Rice Organs at Heading Stage $\left(\mathrm{ugg}^{-1}\right)$. Cd accumulation and distribution in roots, stem, leaves, and grains for all the five cultivars were determined at panicle heading and maturity stages and results presented in Figures 1 and 2. The results 


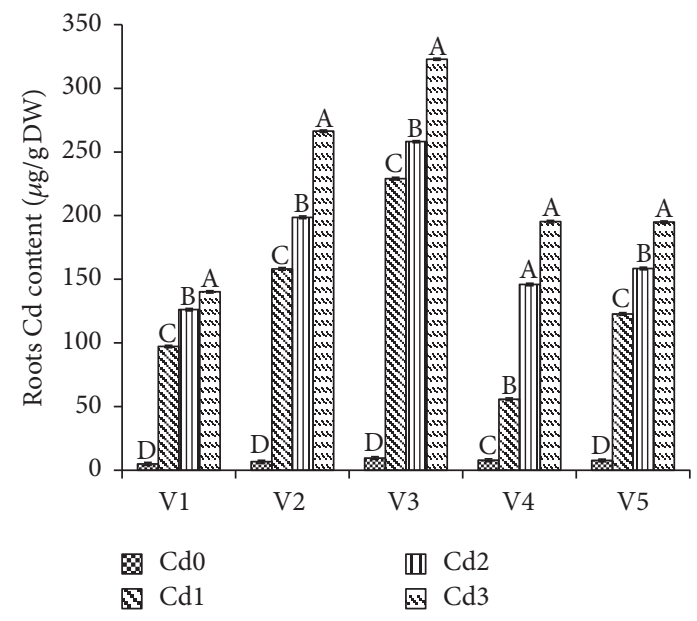

(a)

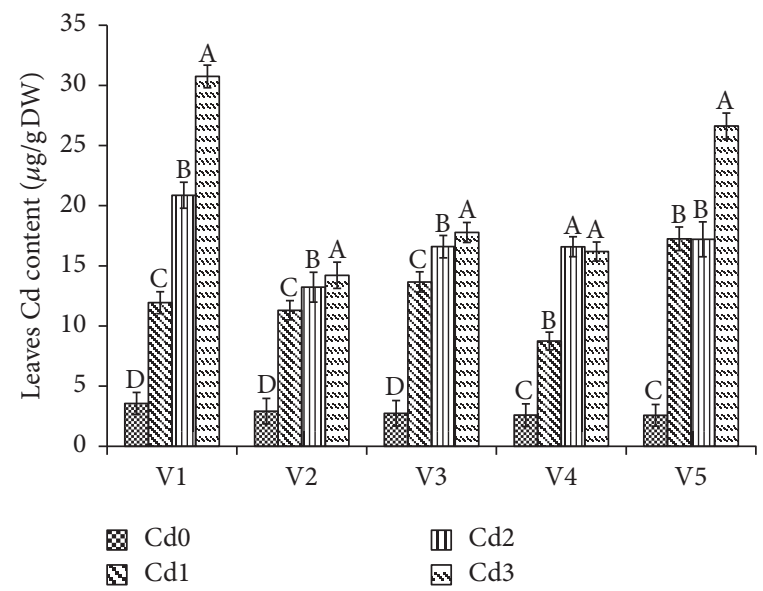

(c)

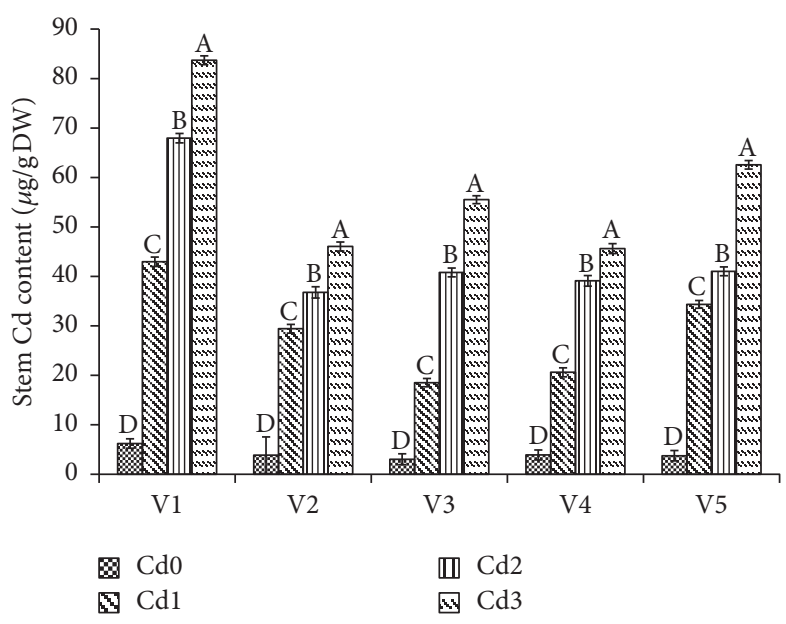

(b)

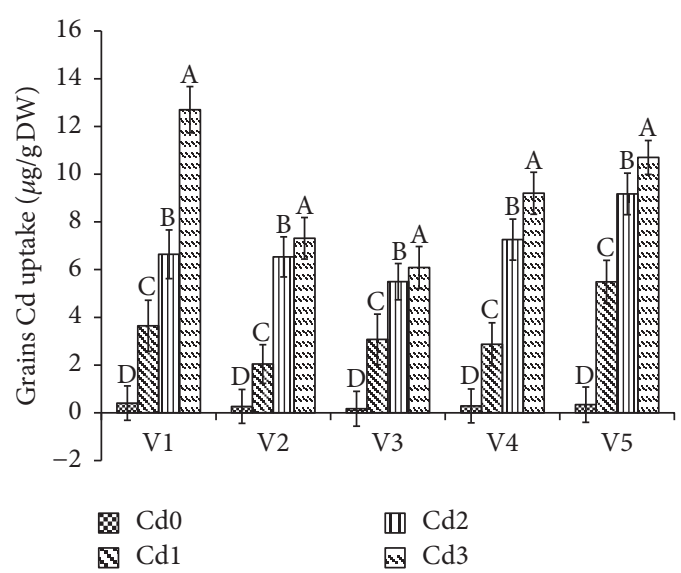

(d)

Figure 2: Cd accumulation in (a) roots, (b) stems, (c) leaves, and (d) grains of the five different rice cultivars under induced Cd stress at maturity stage. The values are representative of three replicated means per treatment \pm SE. Different letters indicate significant differences between treatments at $P \leq 0.05$, LSD.

revealed significant differences in Cd uptake among treatments of the same cultivars. Uptake was found increased in dose dependent manner. With increased soil Cd toxicity, Cd uptake in rice plant parts also increased. At panicle heading stage, Cd uptake was found higher in roots and then stems and less accumulation was observed in leaves. In terms of cultivars ability to accumulate $\mathrm{Cd}$, cultivar 3 accumulated more $\mathrm{Cd}$ in roots and less in stems and leaves, while cultivar 1 accumulated less $\mathrm{Cd}$ in roots and maximum in above-plant parts. Though variation in Cd uptake among the five rice cultivars existed, accumulation differs in $\mathrm{Cd}$ concentrations among the different rice organs of the same plant. The trend of Cd uptake and distribution showed that root accumulated maximum Cd contents followed by shoots and leaves. The accumulated $\mathrm{Cd}$ contents in roots were higher than shoots and leaves in all cultivars. Hence, lower Cd content in roots of some cultivars with higher $\mathrm{Cd}$ in the stems and leaves and, in other cultivars, higher $\mathrm{Cd}$ content in roots with lower $\mathrm{Cd}$ in the stems and leaves indicated the roots ability to uptake maximum and minimum $\mathrm{Cd}$ from the soil and translocate less or more to the stems and leaves. Although greater differences exist in root $\mathrm{Cd}$ accumulation, these differences were found smaller in shoots and leaves. Overall, the values of Cd concentrations in shoots were greatest in Meixiangzhan 2 (V1) compared to the other rice cultivars (Figures 1(a), 1(b), and $1(\mathrm{c}))$.

During maturity stage (Figures 2(a), 2(b), 2(c), and 2(d)), similar trend in Cd uptake was also observed in all cultivars and organs of the same plant as in panicle heading stage. With increased level of Cd induced in the soil, Cd uptake in roots, stems, leaves, and grains was found elevated. Cd uptake was found higher in roots and lower in above-ground plants part with V3 and V2 cultivars accumulating more Cd in roots and less in shoots and grains compared to the other cultivars, while cultivars vl and v5 accumulated less Cd in roots and higher in shoots and grains. This can be as a result of cultivars tolerance or sensitive ability in uptaking and translocating $\mathrm{Cd}$ to plant parts under $\mathrm{Cd}$ stress conditions. 
TABLE 1: Translocation factor (TF) of Cd contents between organs of the five different rice cultivars at panicle heading and maturity stages.

\begin{tabular}{|c|c|c|c|c|c|c|}
\hline \multirow{2}{*}{ Variety } & \multirow{2}{*}{ Treatment } & \multicolumn{2}{|c|}{ Panicle heading stage } & \multicolumn{3}{|c|}{ Maturity stage } \\
\hline & & Roots-stems $_{\mathrm{TF}}$ & Stems- leaves $_{\mathrm{TF}}$ & Roots-stems $\mathrm{TF}_{\mathrm{TF}}$ & Stems- leaves $_{\mathrm{TF}}$ & Leaves-grains $_{\mathrm{TF}}$ \\
\hline \multirow{4}{*}{ V1 } & $\mathrm{Cd} 0$ & 0.552 & 0.435 & 0.605 & 0.846 & 0.114 \\
\hline & Cd1 & 0.167 & 0.336 & 0.442 & 0.278 & 0.305 \\
\hline & $\mathrm{Cd} 2$ & 0.140 & 0.495 & 0.539 & 0.307 & 0.318 \\
\hline & $\mathrm{Cd} 3$ & 0.143 & 0.420 & 0.597 & 0.367 & 0.413 \\
\hline \multirow{4}{*}{$\mathrm{V} 2$} & $\mathrm{Cd} 0$ & 0.641 & 0.590 & 0.573 & 0.759 & 0.092 \\
\hline & Cd1 & 0.235 & 0.308 & 0.186 & 0.384 & 0.181 \\
\hline & $\mathrm{Cd} 2$ & 0.237 & 0.313 & 0.185 & 0.360 & 0.494 \\
\hline & $\mathrm{Cd} 3$ & 0.221 & 0.289 & 0.173 & 0.309 & 0.514 \\
\hline \multirow{4}{*}{ V3 } & $\mathrm{Cd} 0$ & 0.691 & 0.572 & 0.611 & 0.904 & 0.062 \\
\hline & $\mathrm{Cd} 1$ & 0.197 & 0.396 & 0.191 & 0.738 & 0.225 \\
\hline & $\mathrm{Cd} 2$ & 0.316 & 0.254 & 0.323 & 0.407 & 0.331 \\
\hline & $\mathrm{Cd} 3$ & 0.339 & 0.253 & 0.396 & 0.320 & 0.343 \\
\hline \multirow{4}{*}{$\mathrm{V} 4$} & $\mathrm{Cd} 0$ & 0.567 & 0.403 & 0.369 & 0.893 & 0.112 \\
\hline & Cd1 & 0.384 & 0.452 & 0.370 & 0.425 & 0.328 \\
\hline & $\mathrm{Cd} 2$ & 0.207 & 0.600 & 0.268 & 0.424 & 0.437 \\
\hline & $\mathrm{Cd} 3$ & 0.181 & 0.757 & 0.234 & 0.355 & 0.568 \\
\hline \multirow{4}{*}{ V5 } & $\mathrm{Cd} 0$ & 0.494 & 0.659 & 0.487 & 0.687 & 0.132 \\
\hline & Cd1 & 0.192 & 0.369 & 0.280 & 0.502 & 0.318 \\
\hline & $\mathrm{Cd} 2$ & 0.191 & 0.468 & 0.259 & 0.419 & 0.533 \\
\hline & $\mathrm{Cd} 3$ & 0.220 & 0.670 & 0.321 & 0.426 & 0.402 \\
\hline
\end{tabular}

$\mathrm{V}_{n}=$ variety $n, \mathrm{Cd} 0=0 \mathrm{mg} \mathrm{Cd} / \mathrm{kg}, \mathrm{Cd} 1=50 \mathrm{mg} \mathrm{Cd} / \mathrm{kg}, \mathrm{Cd} 2=100 \mathrm{mg} \mathrm{Cd} / \mathrm{kg}$, and Cd $3=150 \mathrm{mg} \mathrm{Cd} / \mathrm{kg}$.

3.2. Translocation Factor (TF) of Cd Contents between Organs of the Five Different Rice Cultivars at Panicle Heading and Maturity Stages. Cd translocation factors from roots to stems, stems to leaves, and leaves to grains were computed and presented in Table 1. Translocation factor varies during the panicle heading and maturity stages. The values were found higher in stems to leaves transference than roots to stems at all levels of $\mathrm{Cd}$ treatments. Across cultivars, highest values for $\mathrm{Cd}$ translocation from roots to shoots and from shoots to leaves were noticed in varieties 3,4 , and 2 respectively, while translocation from roots to shoots and grain in cultivars v3 and v2 was minimal compared to the other cultivars; this is as a result of the cultivars ability to accumulate maximum $\mathrm{Cd}$ in roots and transfer less to shoots.

\subsection{Effects of Cadmium on Yield and Its Parameters. Yield} and yield related parameters were determined after entire rice was harvested and the results are shown in Table 2. There was a variation in yield and its parameters for all cultivars and treatments of the same cultivars. In terms of cultivars performance, maximum number of panicles, spikelet per panicle, 1000 grains' weight, seed setting, and grain yield were observed in cultivar 3 (V3), followed by cultivar 1 (V1), while minimum number of panicles, spikelet per panicle, 1000 grains' weight, seed setting, and grain yield were observed in cultivar 5 (V5) and cultivar 2 (V2). This shows cultivars performance variation when subjected to the same conditions and agronomic practices. On treatments bases, variation in number of panicles, spikelet per panicle, 1000 grains' weight, seed setting, and grain yield among treatments were dose dependent. With increased level of soil Cd toxicity, number of panicles per pot, spikelet per panicle, 1000 grains' weight, seed setting, and grain yield decreased. For grain yield, when compared to control $34.37,43.25$, and $63.85 \%$ yield decrease

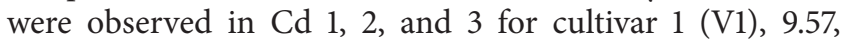
31.09 , and $39.02 \%$ for cultivar 2 (V2), 10.82, 23.51, and 39.95\% for cultivar 3 (V3), 12.43, 22.66, and $31.33 \%$ for cultivar 4 (V4), and 29.14, 46.16, and $47.66 \%$ for cultivar 5 (V5). With the trend shown above, yield decreased as Cd toxicity levels increased and cultivars 1 and 5 showed maximum yield decrease while cultivars 2,3 , and 4 showed minimal yield decrease. This indicated the toxic consequences of $\mathrm{Cd}$ on rice yield.

3.4. Grain Quality Attributes as Influenced by Cd Toxicity. Aromatic rice quality attributes are a significant aspect in rice cultivation and production due to the high price it commands in the market and its desirability by many customers. Hence, quality attributes of fragrant rice cultivated under induced Cd stress conditions were evaluated and results presented in Table 3. Cadmium toxicity greatly affected rice quality attributes in all cultivars. Decreased protein content was observed in all the cultivars subjected under Cd stress conditions. With increased Cd toxic levels, protein contents were also found reduced. Reduction of protein contents in response to $\mathrm{Cd}$ stress was more severe in varieties 1 and 5 (V1 and V5) while minimum reduction was observed in varieties V3, V2, and V4. Higher values (13.29\%) were recorded in cultivar V3 while the least values were recorded in cultivar V5. Amylose contents were also detected and 
TABLE 2: Effects of cadmium on yield and its parameters.

\begin{tabular}{|c|c|c|c|c|c|c|}
\hline Variety & Treatment & Panicles/pot & Spikelet number/pot & 100-grain weight $(\mathrm{g})$ & Seed setting rate (\%) & Grain yield/pot (g) \\
\hline \multirow{4}{*}{ V1 } & $\mathrm{Cd} 0$ & $30.33 \pm 0.33^{\mathrm{a}}$ & $121.07 \pm 0.58^{\mathrm{bc}}$ & $23.97 \pm 0.33^{\mathrm{a}}$ & $89.1 \pm 0.11^{\mathrm{a}}$ & $78.44 \pm 1.40^{\mathrm{a}}$ \\
\hline & Cd1 & $23.66 \pm 0.88^{\mathrm{b}}$ & $127.52 \pm 3.88^{\mathrm{b}}$ & $19.88 \pm 0.38^{b}$ & $85.963 \pm 1.45^{\mathrm{b}}$ & $51.48 \pm 1.61^{\mathrm{b}}$ \\
\hline & $\mathrm{Cd} 2$ & $20.00 \pm 0.57^{\mathrm{c}}$ & $142.34 \pm 2.87^{\mathrm{a}}$ & $19.03 \pm 0.32^{b c}$ & $82.293 \pm 0.74^{c}$ & $44.51 \pm 0.48^{\mathrm{c}}$ \\
\hline & $\mathrm{Cd} 3$ & $17.33 \pm 0.88^{\mathrm{d}}$ & $113.63 \pm 5.25^{\mathrm{c}}$ & $18.1 \pm 0.11^{c}$ & $79.92 \pm 0.45^{\mathrm{c}}$ & $28.35 \pm 0.05^{\mathrm{d}}$ \\
\hline \multirow{4}{*}{ V2 } & $\mathrm{Cd} 0$ & $27.67 \pm 0.33^{\mathrm{a}}$ & $116.35 \pm 2.46^{c}$ & $23.60 \pm 0.28^{\mathrm{a}}$ & $92.32 \pm 0.84^{\mathrm{a}}$ & $70.12 \pm 1.60^{\mathrm{a}}$ \\
\hline & $\mathrm{Cd} 1$ & $25.33 \pm 0.33^{\mathrm{b}}$ & $132.01 \pm 2.39^{\mathrm{ab}}$ & $21.55 \pm 0.17^{\mathrm{b}}$ & $87.86 \pm 1.49^{b}$ & $63.41 \pm 2.69^{\mathrm{b}}$ \\
\hline & $\mathrm{Cd} 2$ & $23.66 \pm 0.33^{c}$ & $123.49 \pm 2.58^{\mathrm{bc}}$ & $19.05 \pm 0.47^{c}$ & $86.883 \pm 0.32^{\mathrm{b}}$ & $48.31 \pm 0.66^{c}$ \\
\hline & $\mathrm{Cd} 3$ & $20.33 \pm 0.66^{\mathrm{d}}$ & $140.32 \pm 7.90^{\mathrm{a}}$ & $18.63 \pm 0.19^{c}$ & $80.697 \pm 1.15^{\mathrm{c}}$ & $42.75 \pm 1.38^{\mathrm{c}}$ \\
\hline \multirow{4}{*}{ V3 } & $\mathrm{Cd} 0$ & $32.33 \pm 0.33^{\mathrm{a}}$ & $113.11 \pm 2.03^{\mathrm{a}}$ & $24.98 \pm 0.24^{\mathrm{a}}$ & $93.79 \pm 0.72^{\mathrm{a}}$ & $85.63 \pm 1.01^{\mathrm{a}}$ \\
\hline & Cd1 & $31.66 \pm 0.33^{\mathrm{a}}$ & $111.66 \pm 0.70^{\mathrm{a}}$ & $24.03 \pm 0.12^{\mathrm{ab}}$ & $89.90 \pm 0.25^{\mathrm{b}}$ & $76.37 \pm 0.19^{b}$ \\
\hline & $\mathrm{Cd} 2$ & $28.67 \pm 0.33^{\mathrm{b}}$ & $110.93 \pm 0.14^{\mathrm{a}}$ & $23.38 \pm 0.47^{\mathrm{bc}}$ & $88.12 \pm 0.42^{c}$ & $65.5 \pm 0.73^{c}$ \\
\hline & $\mathrm{Cd} 3$ & $26.66 \pm 0.33^{c}$ & $98.58 \pm 2.15^{\mathrm{b}}$ & $22.66 \pm 0.33^{c}$ & $86.22 \pm 0.43^{\mathrm{d}}$ & $51.42 \pm 2.10^{\mathrm{d}}$ \\
\hline \multirow{4}{*}{$\mathrm{V} 4$} & $\mathrm{Cd} 0$ & $25.66 \pm 0.33^{\mathrm{a}}$ & $131.33 \pm 3.60^{\mathrm{b}}$ & $22.44 \pm 0.67^{\mathrm{a}}$ & $90.29 \pm 0.96^{\mathrm{a}}$ & $68.37 \pm 3.59^{\mathrm{a}}$ \\
\hline & $\mathrm{Cd} 1$ & $23.33 \pm 0.33^{\mathrm{b}}$ & $139.15 \pm 1.73^{\mathrm{ab}}$ & $21.05 \pm 0.49^{\mathrm{ab}}$ & $87.67 \pm 1.03^{\mathrm{a}}$ & $59.87 \pm 1.46^{\mathrm{b}}$ \\
\hline & $\mathrm{Cd} 2$ & $21.66 \pm 0.33^{\mathrm{c}}$ & $148.57 \pm 6.18^{\mathrm{a}}$ & $19.66 \pm 0.22^{\mathrm{bc}}$ & $83.54 \pm 0.74^{\mathrm{b}}$ & $52.87 \pm 2.43^{\mathrm{bc}}$ \\
\hline & $\mathrm{Cd} 3$ & $19.66 \pm 0.33^{\mathrm{d}}$ & $150.92 \pm 3.72^{\mathrm{a}}$ & $19.30 \pm 0.60^{c}$ & $81.99 \pm 0.47^{\mathrm{b}}$ & $46.95 \pm 1.73^{c}$ \\
\hline \multirow{4}{*}{ V5 } & $\mathrm{Cd} 0$ & $27.66 \pm 0.33^{\mathrm{a}}$ & $130.58 \pm 0.53^{\mathrm{ab}}$ & $24.04 \pm 0.50^{\mathrm{a}}$ & $89.70 \pm 0.55^{\mathrm{a}}$ & $77.9 \pm 1.43^{\mathrm{a}}$ \\
\hline & Cd1 & $25 \pm 0.5774^{\mathrm{b}}$ & $117.65 \pm 0.60^{\mathrm{bc}}$ & $23.44 \pm 0.10^{\mathrm{a}}$ & $80.05 \pm 0.77^{b}$ & $55.19 \pm 1.42^{\mathrm{b}}$ \\
\hline & $\mathrm{Cd} 2$ & $24.33 \pm 0.66^{\mathrm{b}}$ & $103.53 \pm 11.81^{c}$ & $21.83 \pm 0.56^{\mathrm{b}}$ & $77.13 \pm 3.54^{\mathrm{b}}$ & $41.94 \pm 3.22^{c}$ \\
\hline & $\mathrm{Cd} 3$ & $18.33 \pm 0.66^{\mathrm{c}}$ & $147.21 \pm 4.34^{\mathrm{a}}$ & $19.65 \pm 0.21^{c}$ & $76.98 \pm 1.52^{\mathrm{b}}$ & $40.77 \pm 1.36^{\mathrm{c}}$ \\
\hline
\end{tabular}

Three replicated means $( \pm \mathrm{SE})$ were calculated for each treatment. Values with different letters are significantly different at $P<0.05 . \mathrm{V}_{n}=$ variety $n, \mathrm{Cd} 0=$ $0 \mathrm{mg} \mathrm{Cd} / \mathrm{kg}, \mathrm{Cd} 1=50 \mathrm{mg} \mathrm{Cd} / \mathrm{kg}, \mathrm{Cd} 2=100 \mathrm{mg} \mathrm{Cd} / \mathrm{kg}$, and Cd $3=150 \mathrm{mg} \mathrm{Cd} / \mathrm{kg}$.

significant differences were observed among treatments. A reduction in the amylose contents was observed as the $\mathrm{Cd}$ toxic levels increased. Cultivars V3, V2, and V4 were less affected when compared to cultivars V1 and V5, whose decrease in amylose contents was higher. Maximum contents of amylose were recorded in cultivars V3 and V2. Brown rice rate was also determined and the results showed significant differences among treatments. Higher values of brown rice rate were recorded in cultivar $\mathrm{V} 3$ while minimum values were recorded in cultivar V5. With induced soil Cd toxicity, percentage of brown rice was found reduced and maximum reduction was observed in cultivar $\mathrm{V} 1$ while minimum decrease was observed in cultivar V3. Milled rice percentage was also determined and significant decreases were observed among the treatments. Increase in soil $\mathrm{Cd}$ toxicity resulted in declined milled rice rate. Cultivar V3 exhibited higher milled rice values when compared to the other cultivars, while, cultivars V1 and V5 had lower values. The influence of $\mathrm{Cd}$ on milled rice rate greatly affected cultivars $\mathrm{V} 1$ and V5. Chalkiness is a significant rice quality character. Grains chalkiness was estimated and significant differences were observed among the treatments for all cultivars. As $\mathrm{Cd}$ toxicity increased, rice chalkiness reduced. Decline in grain quality shows that $\mathrm{Cd}$ has an effect on rice grain quality attributes and the level of toxicity greatly affected quality traits.

\section{Discussion}

Soil Cd contamination has tremendous effects on plants as it interferes with plant metabolism and, thus, negatively affects plant growth and development. Hence, Cd interaction with essential metals on uptake and distribution in crops is a public concern. In our experiment, the influence of cadmium toxicity on fragrant rice genotypes and its consequences on yield, yield related parameters, and grain quality were examined in five scented rice cultivars. Significant differences were observed in Cd uptake and distribution among cultivars. Cd uptake and accumulation in roots, stems, leaves, and grains were found higher in V1 and V5 cultivars compared to the other cultivars; this was probably as a result of the higher uptake and translocation ability of the cultivars to absorb $\mathrm{Cd}$ from the soil medium and subsequent translocation to roots and then to above-ground parts. The differences observed in accumulation may be related to the genotypic tolerance nature of the cultivars to cadmium toxicity. Cd uptake showed concentration dependent behavior in which maximum Cd speciation was high at higher Cd concentrations and low under lower Cd concentrations; this is often being influenced by the cultivars root oxidation abilities, root acidifications, and root organic acid secretions [13]. Genotypic variations of $\mathrm{Cd}$ tolerance in rice cultivars have been reported in which $\mathrm{Cd}$ uptake and translocation from contaminated soil to plants edible parts were markedly different among plant species as well as cultivars within the same species [16].

For all treatments and cultivars, the distribution ratios of $\mathrm{Cd}$ concentration in rice organs followed root $>$ stem $>$ leaves > grains. These differences in $\mathrm{Cd}$ concentrations may arise from the variation of Cd uptake and translocation ability of cultivar type. In similar studies, marked positive 


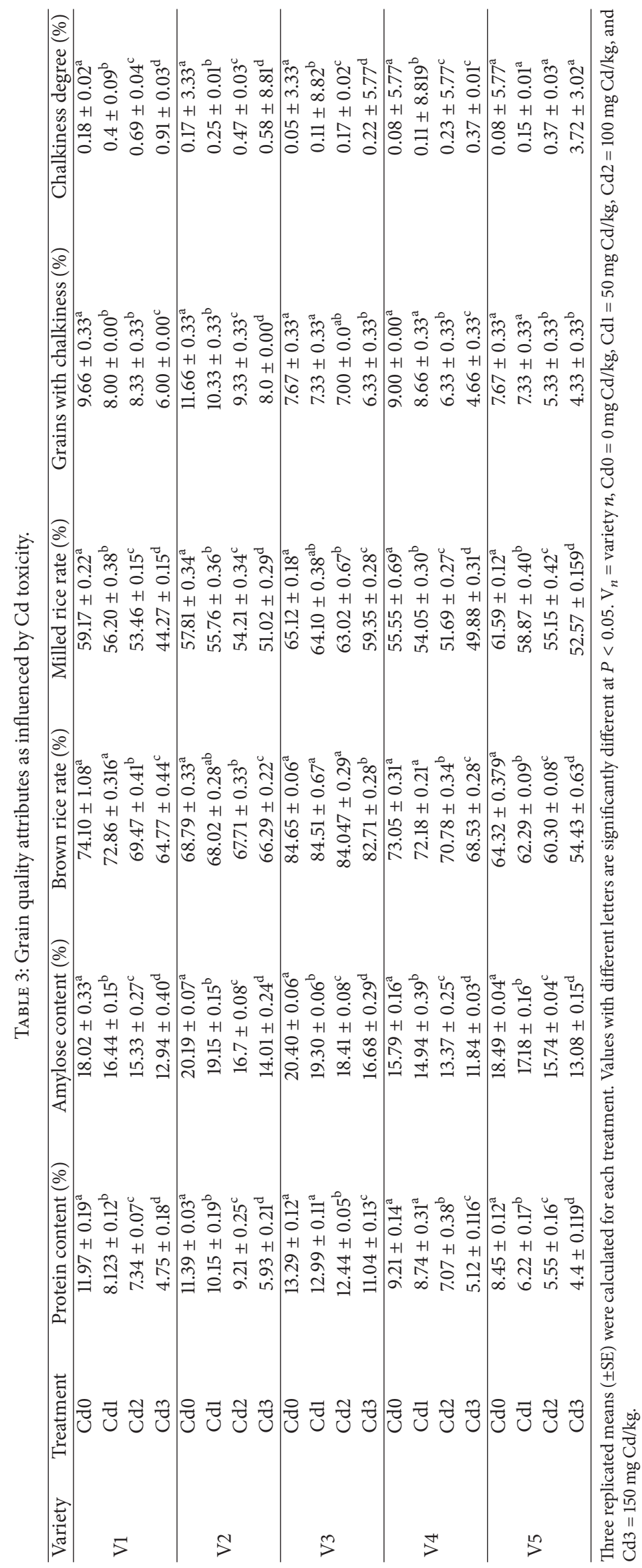


correlations in Cd concentrations were reported between the rice roots, stems leaves, and grains [17], and marked linear correlations between $\mathrm{Cd}$ concentrations in rice grains and straws/roots Cd concentrations $(P<0.01)$ were also shown $[18,19]$. The results in our study further illustrated variations in Cd uptake and translocation among the five cultivars as well as organs of the same cultivar. Rice cultivars with high affinity for soil $\mathrm{Cd}$ responded to high levels of soil Cd by partitioning a greater proportion of total plant $\mathrm{Cd}$ in roots and above-plant parts. The variation of grain $\mathrm{Cd}$ concentration in our experiment depended on root $\mathrm{Cd}$ uptake by rice cultivars and then translocation to aboverice part, particularly shoot to grain translocation. [20], concluded that $\mathrm{Cd}$ translocation from root to shoot via the xylem flow was the main physiological process that determined $\mathrm{Cd}$ accumulation in rice shoots and grains. This suggested that exceeding $\mathrm{Cd}$ translocation from root to shoot via xylem flow led to higher $\mathrm{Cd}$ accumulation in vegetative tissues ("source" organ), as well as higher Cd content transported to grains ("sink" organ) via the phloem. Our results showed that $\mathrm{Cd}$ accumulation in rice organs was aided by physiological processes and genetic expressions; hence, maximum $\mathrm{Cd}$ retention in roots with less translocation to shoots forms an important mechanism in Cd tolerance. The ability of cultivar to retain $\mathrm{Cd}$ in roots can contribute to reduced accumulation of $\mathrm{Cd}$ in grain which is of great significant to human health. As indicated above, cultivars v3 and v2 seem to have higher capacity to accumulate $\mathrm{Cd}$ in roots and less in grains. Rice quality traits to a larger extent do depend on rice plant external environmental conditions including both biotic and abiotic stresses, cultivar genetic makeup, and crop agronomic and management practices employed during growth and in storage. Cd toxicity affected rice quality attributes including grain protein, amylose contents, brown rice accumulation, milled rice percentage, chalkiness \%, and chalkiness area. With increased level of Cd toxicity, brown rice accumulation as well as chalkiness $\%$ and chalkiness area increased, while grain protein, amylose contents, and milled rice rate decreased. These effects were found concentration dependent and cultivar-specific.

\section{Conclusion}

This study was carried out to examine the influence of cadmium toxicity on fragrant rice genotypes and its consequences on yield, yield related parameters, and grain quality traits. Cd uptake, translocation, and speciation in different plant parts were found to be genotype-specific and concentration dependent. Differences existed in Cd absorption, distribution, and accumulation among rice cultivars. Our results further demonstrated that Guixiangzhan cultivar retained more $\mathrm{Cd}$ in roots and less in grains which is more significant to humans. Rice yield and grain quality were also found reduced with increased toxicity level. The overall performance in terms of minimum $\mathrm{Cd}$ uptake and distribution to grain, yield, and grain quality reduction for all the rice cultivars under $\mathrm{Cd}$ stress were recorded as V3 > $\mathrm{V} 2>\mathrm{V} 4>\mathrm{V} 5>\mathrm{V} 1$.

\section{Conflicts of Interest}

The authors have no existing conflicts of interest.

\section{Acknowledgments}

This work was supported by China's Natural Science Foundation (31271646) and the World Bank Loan Agricultural Pollution Control Project in Guangdong (07241510A08N3684), Guangzhou Science and Technology Plan Projects (201707010413), National Natural Science Foundation for Young Scientists (31601244), Guangdong Province Natural Science Foundation (8151064201000017), Guangdong Province Agricultural Research Projects (2011AO20202001), and the Guangdong Province Agricultural Standardization Project (4100 F10003).

\section{References}

[1] M. Rizwan, J.-D. Meunier, H. Miche, and C. Keller, "Effect of silicon on reducing cadmium toxicity in durum wheat (Triticum turgidum L. cv. Claudio W.) grown in a soil with aged contamination," Journal of Hazardous Materials, vol. 209-210, pp. 326-334, 2012.

[2] F. Douay, C. Pruvot, C. Waterlot et al., "Contamination of woody habitat soils around a former lead smelter in the North of France," Science of the Total Environment, vol. 407, no. 21, pp. 5564-5577, 2009.

[3] M. Rizwan, S. Ali, M. Adrees et al., "Cadmium stress in rice: toxic effects, tolerance mechanisms, and management: a critical review," Environmental Science and Pollution Research, vol. 23, no. 18, pp. 17859-17879, 2016.

[4] W.-E. Song, S.-B. Chen, J.-F. Liu et al., "Variation of Cd concentration in various rice cultivars and derivation of cadmium toxicity thresholds for paddy soil by species-sensitivity distribution," Journal of Integrative Agriculture, vol. 14, no. 9, pp. 1845-1854, 2015.

[5] U. Ashraf, A. S. Kanu, Z. Mo et al., "Lead toxicity in rice: effects, mechanisms, and mitigation strategies-a mini review," Environmental Science and Pollution Research, vol. 22, no. 23, pp. 18318-18332, 2015.

[6] A. Sebastian and M. N. V. Prasad, "Operative photo assimilation associated proteome modulations are critical for irondependent cadmium tolerance in Oryza sativa L.," Protoplasma, vol. 252, no. 5, pp. 1375-1386, 2015.

[7] P. F. A. M. Römkens, D. J. Brus, H. Y. Guo, C. L. Chu, C. M. Chiang, and G. F. Koopmans, "Impact of model uncertainty on soil quality standards for cadmium in rice paddy fields," Science of the Total Environment, vol. 409, no. 17, pp. 3098-3105, 2011.

[8] X. Xu, Y. Zhao, X. Zhao, Y. Wang, and W. Deng, "Sources of heavy metal pollution in agricultural soils of a rapidly industrializing area in the Yangtze Delta of China," Ecotoxicology and Environmental Safety, vol. 108, pp. 161-167, 2014.

[9] P. Kosolsaksakul, J. G. Farmer, I. W. Oliver, and M. C. Graham, "Geochemical associations and availability of cadmium (Cd) in a paddy field system, northwestern Thailand," Environmental Pollution, vol. 187, pp. 153-161, 2014.

[10] R. K. Srivastava, P. Pandey, R. Rajpoot, A. Rani, and R. S. Dubey, "Cadmium and lead interactive effects on oxidative stress and antioxidative responses in rice seedlings," Protoplasma, vol. 251, no. 5, pp. 1047-1065, 2014. 
[11] F. Yu, K. Liu, M. Li, Z. Zhou, H. Deng, and B. Chen, "Effects of cadmium on enzymatic and non-enzymatic antioxidative defences of rice (oryza sativa L.)," International Journal of Phytoremediation, vol. 15, no. 6, pp. 513-521, 2013.

[12] Y. Wang, X. Jiang, K. Li et al., "Photosynthetic responses of oryza sativa L. seedlings to cadmium stress: physiological, biochemical and ultrastructural analyses," BioMetals, vol. 27, no. 2, pp. 389-401, 2014.

[13] J. Liu, M. Qian, G. Cai, J. Yang, and Q. Zhu, "Uptake and translocation of $\mathrm{Cd}$ in different rice cultivars and the relation with Cd accumulation in rice grain," Journal of Hazardous Materials, vol. 143, no. 1-2, pp. 443-447, 2007.

[14] F. Cao, R. Wang, W. Cheng et al., "Genotypic and environmental variation in cadmium, chromium, lead and copper in rice and approaches for reducing the accumulation," Science of the Total Environment, vol. 496, pp. 275-281, 2014.

[15] C. A. Grant, J. M. Clarke, S. Duguid, and R. L. Chaney, "Selection and breeding of plant cultivars to minimize cadmium accumulation," Science of the Total Environment, vol. 390, no. 23, pp. 301-310, 2008.

[16] M. I. Mattina, W. Lannucci-Berger, C. Musante, and J. C. White, "Concurrent plant uptake of heavy metals and persistent organic pollutants from soil," Environmental Pollution, vol. 124, no. 3, pp. 375-378, 2003.

[17] X. Ye, Y. Ma, and B. Sun, "Influence of soil type and genotype on Cd bioavailability and uptake by rice and implications for food safety," Journal of Environmental Sciences (China), vol. 24, no. 9, pp. 1647-1654, 2012.

[18] J. He, C. Zhu, Y. Ren, Y. Yan, and D. Jiang, "Genotypic variation in grain cadmium concentration of lowland rice," Journal of Plant Nutrition and Soil Science, vol. 169, no. 5, pp. 711-716, 2006.

[19] Y. F. Yan, D. H. Choi, D. S. Kim, and B. W. Lee, "Genotypic variation of cadmium accumulation and distribution in rice," Journal of Crop Science and Biotechnology, vol. 13, pp. 69-73, 2010.

[20] S. Uraguchi, S. Mori, M. Kuramata, A. Kawasaki, T. Arao, and S. Ishikawa, "Root-to-shoot Cd translocation via the xylem is the major process determining shoot and grain cadmium accumulation in rice," Journal of Experimental Botany, vol. 60, no. 9, pp. 2677-2688, 2009. 

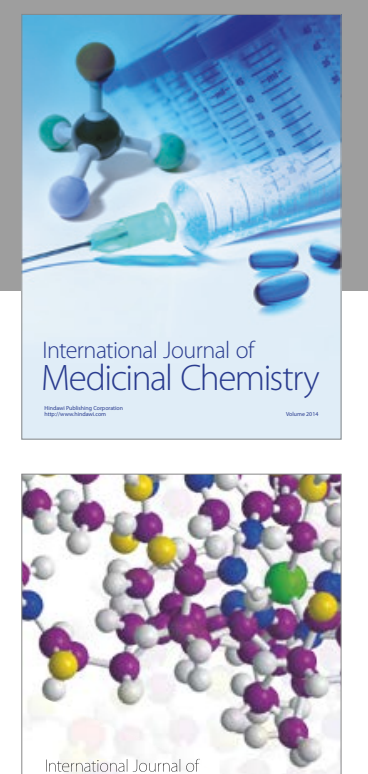

Carbohydrate Chemistry

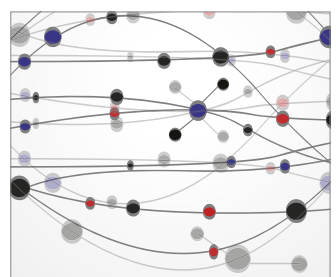

The Scientific World Journal
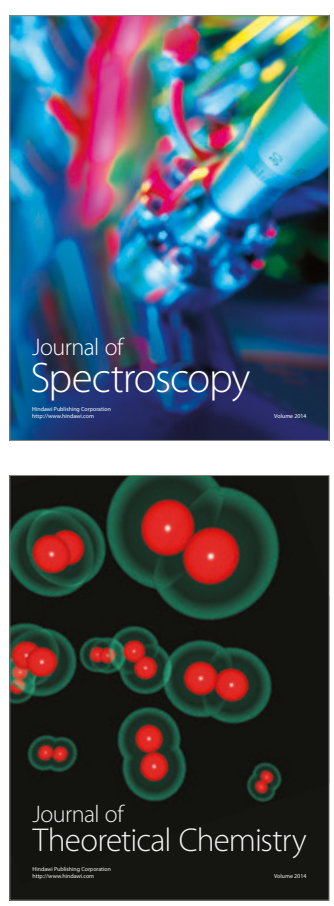
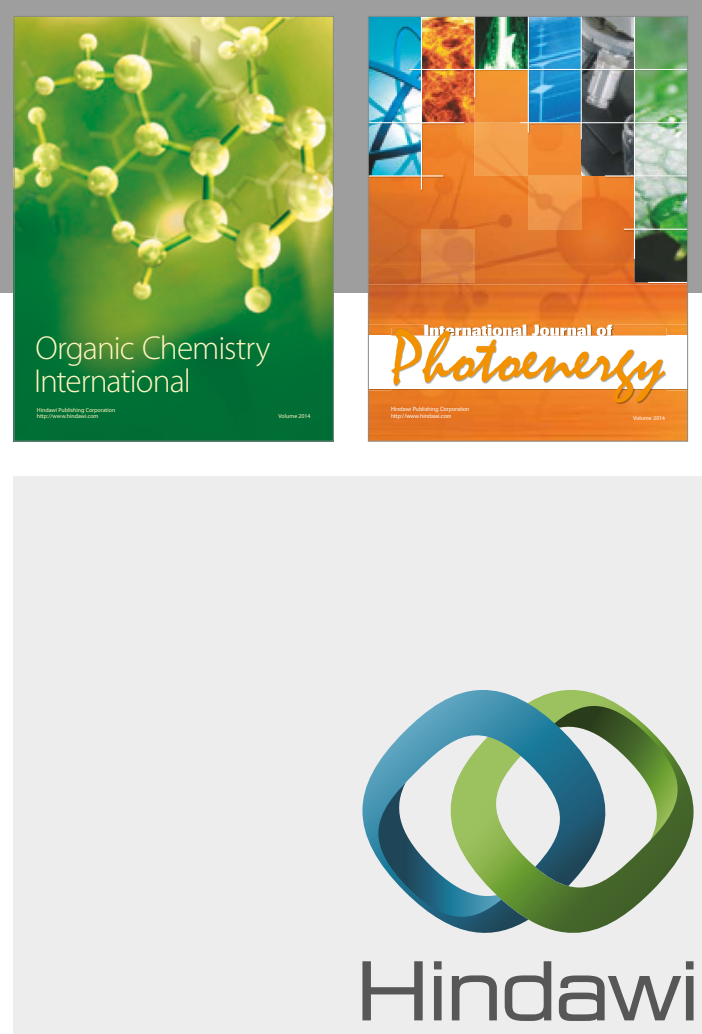

Submit your manuscripts at

https://www.hindawi.com

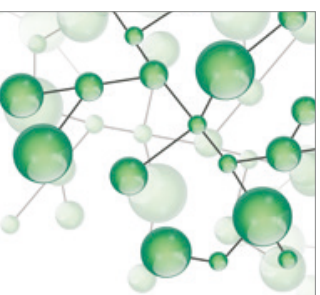

International Journal of

Inorganic Chemistry

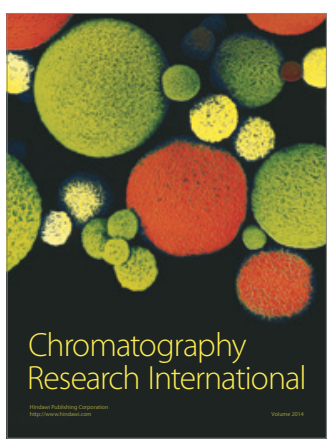

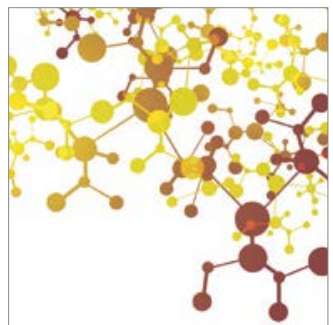

Applied Chemistry
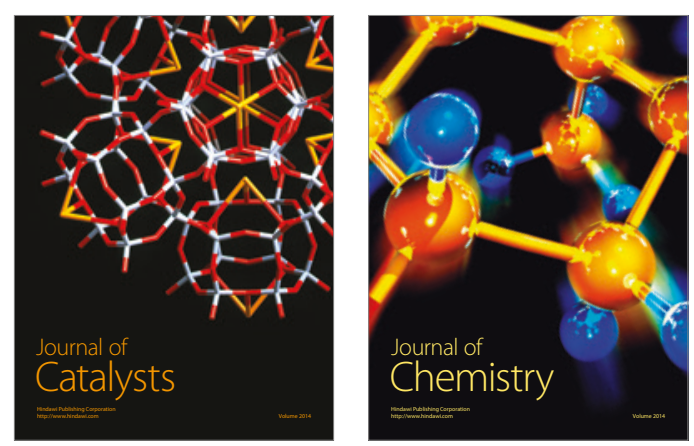
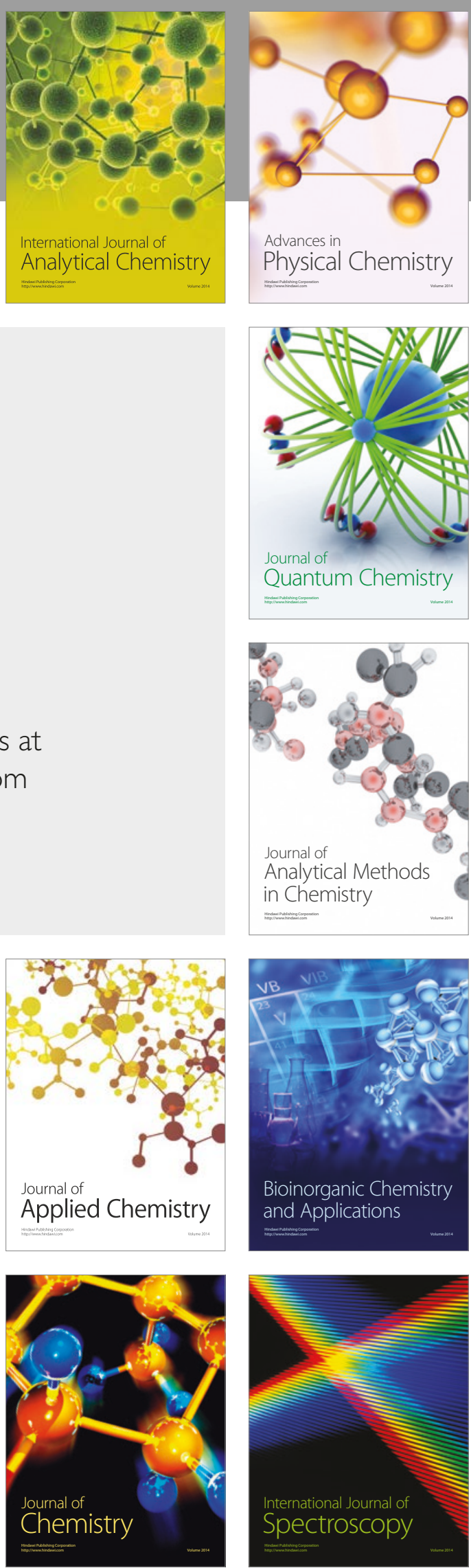